\section{Kidney \\ Blood Pressure \\ Research}

\title{
Administration of Cyclosporine A in Pregnant Rats - the Effect on Blood Pressure and on the Glomerular Number in Their Offspring
}

\author{
Natalia Slabiak-Blaz ${ }^{\mathrm{a}}$ Marcin Adamczak ${ }^{\mathrm{a}} \quad$ Nadezda Gut $^{\mathrm{b}} \quad$ Aniela Grajoszek $^{\mathrm{c}}$ \\ Jens R. Nyengaard ${ }^{d}$ Eberhard Ritz ${ }^{\mathrm{e}}$ Andrzej Wiecek ${ }^{\mathrm{a}}$
}

aDepartment of Nephrology, Transplantation and Internal Medicine, Medical University of Silesia, Katowice, Poland; 'bepartment of Pathology, Memmingen Hospital, Germany; 'Center for Experimental Medicine, Medical University of Silesia in Katowice, Katowice, Poland; 'Stereology and Electron Microscopy Laboratory, Centre for Stochastic Geometry and Advanced Bioimaging, Department of Clinical Medicine, Aarhus University, Aarhus C, Denmark; 'Department of Internal Medicine, Division Nephrology, University of Heidelberg, Heidelberg, Germany

\section{Key Words}

Chronic kidney disease $\cdot$ Pregnant rats $\bullet$ Cyclosporine A $\bullet$ Glomerular number $\bullet$ Hypertension - Kidney development

\begin{abstract}
Background/Aims: Cyclosporine A ( $\mathrm{Cs} A)$ is a commonly used immunosuppressive agent. In some patients treatment with CsA has to be continued during pregnancy. The aim of the study was to assess in an experimental model whether the exposure to CsA during fetal life influences the number and volume of glomeruli, kidney function and blood pressure in the offspring. Methods: Eight pregnant female Sprague-Dawley rats were allocated to 2 treatment regimens: with CsA or solvent. Blood pressure was measured in the offspring at 7 and 11 weeks of age and albuminuria was determined at 11 weeks of age. In the kidney the number and mean volume of glomeruli was assessed using stereological methods. Results: In the offspring of pregnant rats treated with CsA the number of glomeruli was significantly lower and the mean volume of glomeruli was higher when compared to the offspring of pregnant rats receiving solvent. Systolic and diastolic blood pressures as well as albuminuria were significantly higher in the offspring of mothers treated with CsA during gestation compared to the offspring from the control group. Conclusions: Exposure of rats to CsA during fetal life impairs kidney development, thus potentially predisposing to chronic kidney disease and hypertension in the adult life.

Copyright @ 2015 S. Karger AG, Basel

Prof. Andrzej Wiecek M.D., Ph.D., FRCP (Edin.), FERA

Department of Nephrology, Transplantation and Internal Medicine, Medical University of Silesia, Francuska 20-24 Str., 40-027 Katowice (Poland)

Tel.+4832-2552695, Fax +4832-2553726, E-Mail awiecek@spskm.katowice.pl
\end{abstract}




\section{Kidney Blood Pressure Research}

Kidney Blood Press Res 2015;40:413-423

\begin{tabular}{l|l}
\hline DOI: $10.1159 / 000368515$ & (C) 2015 S. Karger AG, Basel
\end{tabular}

Published online: July 27, 2015

www.karger.com/kbr

\section{Introduction}

The hypothesis of "fetal programming" suggests that adverse conditions during fetal life may interfere with organ development, potentially causing permanent structural and functional changes [1], e.g. chronic disease in later life.

Brenner et al. had proposed that individuals with a low nephron number at birth, as a consequence of impaired intrauterine nephrogenesis, are at higher risk of developing hypertension and chronic kidney disease in adulthood [2,3]. A reduced nephron endowment may cause reduced sodium excretory capacity of the kidney with subsequent hypervolemia, enhanced susceptibility to hypertension and reduced renal reserve. Furthermore, glomerular hyperfiltration and hypertrophy in the remaining nephrons may ultimately end up in glomerulosclerosis [4, 5]. Many animal experiments documented that interventions such as protein restriction [6], exposure to glucocorticosteroids [7], vitamin A deficiency [8], and alcohol exposure [9] are associated with a reduced nephron number and, in the long term, with hypertension and renal insufficiency. In humans Keller et al. documented that individuals with primary hypertension had fewer glomeruli and larger glomerular volumes compared with normotensive controls [10].

CsA has been assigned by the FDA to "pregnancy category C" as there are no controlled data in human pregnancy. CsA is not considered to be a teratogen [11]; nevertheless it crosses the placenta [12] and may therefore interfere with fetal development. The toxic effects of CsA on the adult kidney are well-known, but little is known about the potential effects of therapeutic doses of CsA in the developing kidney. When embryonic rat kidneys were cultured in the presence of CsA, differentiation of metanephros was impaired compared to kidneys cultured in control media [13], pointing to an adverse effect of CsA on nephrogenesis in vivo. Only a few human studies with a small number of subjects and short time of observation assessed the influence of CsA exposure during fetal life on kidney development and no abnormalities were documented [14-16].

The present animal experiment adopted a design-unbiased stereologic technique, based on the fractionator/disector principle [17]. The aim was to document whether exposure to CsA during fetal life influences kidney development, especially the number and volume of glomeruli. Additionally kidney function and blood pressure were analyzed after birth.

\section{Materials and Methods}

\section{Animals and study design}

Eight female, 3 months old Sprague-Dawley rats were obtained from the Center of Experimental Medicine, Medical University of Silesia, Katowice, Poland. They were housed singly and kept at a constant room temperature $\left(21 \mathrm{C}^{\circ}\right)$ and humidity (50\%) with exposure to a $12 \mathrm{~h}$ light on, $12 \mathrm{~h}$ light off cycle. They were given free access to tap water and standard rodent chow (Feed Lab., Poland). The female rats were mated according to the harem protocol with one male rat. Pregnancy was diagnosed when semen was detected in the vaginal smear on the first day after mating. Then the animals were allocated to two treatment regimens: the first group $(n=4)$ was treated with CsA $(3.3 \mathrm{mg} / \mathrm{kg} / 24 \mathrm{~h})$; the second group $(\mathrm{n}=4)$ received the corresponding volume of solvent $(0.9 \% \mathrm{NaCl} ; 1 \mathrm{ml} / \mathrm{kg} / 24 \mathrm{~h})$. Both CsA or solvent $(0.9 \% \mathrm{NaCl})$ were administered subcutaneously, once daily, from the $10^{\text {th }}$ day after the fertilization till the $7^{\text {th }}$ day after the delivery.

The CsA dose was based on our pharmacokinetic study on CsA given subcutaneously in SpragueDawley rats [18]. In all pregnant rats tail artery blood pressure was measured indirectly under isoflurane anesthesia on the $20^{\text {th }}$ day of gestation using the CODA System (Kent Scientific, Connecticut, USA). The isoflurane anesthesia was shallow, performed only until the first signs of spontaneous limbs and tail movements lessened. Experiments with different anesthetics: isoflurane, ketamine and tiopental and isoflurane showed that isoflurane has no or only minimal effect on blood pressure compared to other drugs during shallow anesthesia in Sprague-Dawley rats (data not published). The pups were weighed $48 \mathrm{~h}$ after delivery. After delivery the pups were kept with their mothers until weaning at 4 weeks. Thereafter, male 


\section{Kidney \\ Blood Pressure Research}

Kidney Blood Press Res 2015;40:413-423

\begin{tabular}{l|l}
\hline DOI: 10.1159/000368515 & (C) 2015 S. Karger AG, Basel
\end{tabular}

Published online: July 27, 2015

www.karger.com/kbr

and female offspring were kept in separate cages and weighed weekly. At 7 and 11 weeks of age systolic and diastolic blood pressure was assessed again in the offspring of both groups using the above mentioned CODA System (Kent Scientific, Connecticut, USA). At 11 weeks of age the rats were placed individually in a metabolic cage for 24 hours urine collection. Twelve weeks after delivery the experiment was terminated: the rats were anesthetized with ketamine $\mathrm{HCl}(40 \mathrm{mg} / 100 \mathrm{~g}$ body mass, intramuscular) and $2 \%$ xylazine $(0.5 \mathrm{ml} / \mathrm{kg}$ body mass, intramuscular); subsequently, the abdominal aorta was catheterized, blood samples were taken and retrograde aortic perfusion with Ringer solution was followed by $4 \%$ phosphate-buffered formaldehyde. The kidneys were removed and weighed after the capsule and perihilar fat had been taken off. The protocol was approved by the Animal Ethics Committee of the Medical University of Silesia in Katowice (No 52/2007, 36/2008, 10/2009). The experiment was conducted with adherence to the National Institutes of Health Guide for the Care and Use of Laboratory Animals.

\section{Blood and urine analysis}

In the collected blood samples the concentration of serum creatinine was determined using standard laboratory methods. In the 24-hours urine collections the concentration of creatinine was measured using standard laboratory methods and albuminuria using the rat specific ELISA (ICL Inc. Newberg, USA).

\section{Morphological analysis}

The number and volume of glomeruli was assessed using the design-unbiased stereological method the physical fractionator/disector. The left kidney was used for estimating glomerular number and volume. Kidneys were stored in $4 \%$ phosphate-buffered formaldehyde for at least 2 weeks before tissue preparation. The kidneys were then embedded in glycolmethacrylate (Technovit 7100; HeraeusKulzer, Germany) followed by 4 step embedding procedure: dehydratation in graded ethanol, preinfiltration, infiltration and polymerization. With the use of a Microm HM 355 microtome, each kidney was cut in $10 \mu \mathrm{m}$-thick coronal sections. With the use of the fractionator technique every 80th section and its adjacent section were selected for estimation of glomerular number, providing a section sampling fraction (SSF) of 1/80. The sampled sections were mounted on a slide and stained with PAS. On average, 9 or 10 section pairs per kidney were mounted. Counting was performed with the use of newCAST software (Visiopharm, Hørsholm, Denmark) and a microscope Olympus BX-50 (Olympus, Tokyo, Japan) with an automated specimen stage Märzhäuser Multi Control 2000 (Märzhäuser, Wetzlar-Steindorf, Germany) and digital camera (Pixelink PL-A686C). The paired sampled sections were positioned together on the specimen stage and the region of interest was drawn around both sections. After determination of the corresponding areas on both sections (with the use of small vessels as landmarks) and after $\mathrm{x}$ - and $\mathrm{y}$-step lengths $(3000 \mu \mathrm{m})$ were defined, the counting grid was randomly oriented and placed on the sections. Glomeruli were counted in 5-6 section pairs starting with the third section pair (glomeruli were not counted in the two first and two last section pairs because of the artificial edges in the z-direction in these sections). The glomeruli (Q-) were counted when they were present inside the two-dimensional unbiased counting frame in one section (the sampling frame), but not in the adjacent section plane (the look-up section), and vice versa.

The total number of glomeruli per kidney N(glom), mean glomerular volume Vn(glom) and total glomerular volume V(glomTotal) was calculated-as described previously [17, 19]. In the same PAS stained sections a qualitative analysis of glomerular, tubulointerstitial and vascular damage was performed at a magnification of X 100.

\section{Statistical analysis}

All results concerning offspring are presented as mean $\pm \mathrm{SD}$; data concerning mothers are presented as mean and range. Mann-Whitney U test was used to compare nonparametric continuous variables between groups.

\section{Results}

Dams

There were no significant differences between dams in both groups (Table 1). Treatment with $\mathrm{CsA}$ or solvent $(0.9 \% \mathrm{NaCl})$ did not influence blood pressure during pregnancy 


\section{Kidney \\ Blood Pressure Research}

\section{Kidney Blood Press Res 2015;40:413-423}

DOI: 10.1159/000368515

Published online: July 27, 2015

(C) 2015 S. Karger AG, Basel

www.karger.com/kbr

Slabiak-Blaz/Adamczak/Gut/Grajoszek/Nyengaard/Ritz/Wiecek: Cyclosporine A and Kidney Development

Table 1. Characteristics of mother rats exposed to CsA or to solvent (control group) mean value; (range)

\begin{tabular}{lcc}
\hline & Exposed group $\mathrm{n}=4$ & Control group $\mathrm{n}=4$ \\
\hline Body weight $[\mathrm{g}]$ & $299 ;(264-354)$ & $316 ;(298-333)$ \\
$\begin{array}{l}\text { Systolic/diastolic blood pressure before } \\
\text { conception [mmHg] }\end{array}$ & $113 ;(111-117) / 77 ;(74-80)$ & $111 ;(109-113) / 76 ;(75-77)$ \\
Systolic/diastolic blood pressure at day 20 of & $118 ;(111-130) / 80 ;(77-85)$ & $114 ;(106-127) / 78 ;(69-85)$ \\
gestation [mmHg] & $29.3 ;(20-44)$ & $25.3 ;(23-28)$ \\
Serum creatinine concentration [ $\mu \mathrm{mol} / \mathrm{l}]$ & $1.2 ;(1,1-1,3)$ & $1.2 ;(1,1-1,3)$ \\
Kidney weight $[\mathrm{g}]$ & $23640 ;(21659-25044)$ & $23660 ;(23377-23852)$ \\
Number of glomeruli in kidney [n] & $1.8 ;(1,7-2,1)$ & $1.8 ;(1,6-2,0)$ \\
Mean volume of glomeruli in kidney $\left[10^{6} \mu \mathrm{m}^{3}\right]$ &
\end{tabular}

Table 2. Pregnancy outcomes in rats exposed to CsA or to solvent (control group) (All data, except "Offspring body weight 48 hours after delivery", presented as mean value; (range), Offspring body weight 48 hours after delivery presented as mean $\pm \mathrm{SD}$ ); ${ }^{*} \mathrm{p}<0.05$ vs control group

\begin{tabular}{lcc}
\hline & Exposed group $\mathrm{n}=4$ & Control group $\mathrm{n}=4$ \\
\hline Duration of pregnancy [days] & $23.8 ;(23-24)^{*}$ & $22.5 ;(22-23)$ \\
Offspring numbers per litter [n] & $8.0 ;(5-10)$ & $7.8 ;(4-10)$ \\
Offspring body weight 48 hours after delivery[g] & $8.9 \pm 0.6^{*}$ & $8.4 \pm 0.8$ \\
Male offspring litter [n] & $5.8 ;(3-8)$ & $3.7 ;(3-5)$ \\
Female offspring litter [n] & $2.3 ;(2-3)$ & $4.0 ;(1-5)$ \\
\hline
\end{tabular}

Table 3. Controlled study on postpartal development of rat offspring with a history of in utero exposure to CsA compared to controls with exposure to solvent (mean $\pm \mathrm{SD}$ ); ${ }^{*} \mathrm{p}<0.05, \dagger \mathrm{p}<0.01, \neq \mathrm{p}<0.001$ vs control group

\begin{tabular}{|c|c|c|c|c|c|c|}
\hline & \multicolumn{3}{|c|}{ Exposed group } & \multicolumn{3}{|c|}{ Control group } \\
\hline & $\begin{array}{l}\text { Entire group } \\
n=32\end{array}$ & $\begin{array}{c}\text { Female } \\
\mathrm{n}=9\end{array}$ & $\begin{array}{l}\text { Male } \\
\mathrm{n}=23\end{array}$ & $\begin{array}{c}\text { Entire group } \\
n=31\end{array}$ & $\begin{array}{c}\text { Female } \\
\mathrm{n}=15\end{array}$ & $\begin{array}{l}\text { Male } \\
\mathrm{n}=16\end{array}$ \\
\hline $\begin{array}{l}\text { Body weight } \\
\text { at } 12 \text { weeks of age [g] }\end{array}$ & $319 \pm 72$ & $256 \pm 18$ & $343 \pm 70$ & $341 \pm 69$ & $250 \pm 12$ & $375 \pm 35$ \\
\hline $\begin{array}{l}\text { Kidney weight } \\
\text { at } 12 \text { weeks of age }[\mathrm{g}]\end{array}$ & $1.36 \pm 0.27$ & $1.15 \pm 0.07 \dagger$ & $1.45 \pm 0.27$ & $1.36 \pm 0.34$ & $1.05 \pm 0.08$ & $1.65 \pm 0.19$ \\
\hline $\begin{array}{l}\text { Systolic/diastolic blood pressure } \\
\text { at } 7 \text { weeks of age }[\mathrm{mmHg}]\end{array}$ & $125 \pm 5 \ddagger / 82 \pm 6 \ddagger$ & $: 124 \pm 6 \ddagger / 83 \pm 6 \dagger$ & $125 \pm 5 \ddagger / 82 \pm 6$ & $117 \pm 6 / 77 \pm 6$ & $115 \pm 3 / 76 \pm 4$ & $118 \pm 7 / 78 \pm 7$ \\
\hline $\begin{array}{l}\text { Systolic/diastolic blood pressure } \\
\text { at } 11 \text { weeks of age [mmHg] }\end{array}$ & $130 \pm 9 * / 89 \pm 8 \dagger$ & $128 \pm 7 / 88 \pm 7 \dagger$ & $131 \pm 9 / 90 \pm 9$ & $127 \pm 6 / 84 \pm 6$ & $123 \pm 4 / 80 \pm 5$ & $130 \pm 6 / 86 \pm 6$ \\
\hline $\begin{array}{l}\text { Albuminuria } \\
{[\mu \mathrm{g} / 24 \text { hours }]}\end{array}$ & $14.2 \pm 25.0^{*}$ & $12.3 \pm 17.3^{*}$ & $14.9 \pm 28.6$ & $4.5 \pm 4.5$ & $3.2 \pm 2.2$ & $5.6 \pm 5.7$ \\
\hline $\begin{array}{l}\text { Serum creatinine concentration } \\
{[\mu \mathrm{mol} / \mathrm{l}]}\end{array}$ & $17.5 \pm 8.4$ & $15.8 \pm 7.5$ & $18.1 \pm 9$ & $17.9 \pm 5.0$ & $16.8 \pm 3.5$ & $19.1 \pm 6$ \\
\hline $\begin{array}{l}\text { Creatinine clearance } \\
{[\mathrm{ml} / \mathrm{min}]}\end{array}$ & $2.59 \pm 2.44$ & $2.67 \pm 1.4$ & $2.98 \pm 2.54$ & $2.45 \pm 1.56$ & $2.1 \pm 1.0$ & $3.4 \pm 1.3$ \\
\hline
\end{tabular}

(Table 1). The pregnancy was significantly longer in the group of rats treated with CsA compared to the rats receiving $0.9 \% \mathrm{NaCl}(\mathrm{p}<0.05)$ (Table 2).

Offspring data: litter size, body weight, kidney weight

There was no significant difference in mean litter size and sex distribution between the dams exposed to CsA and the control group (Table 2). The body weight of the offspring was assessed $48 \mathrm{~h}$ after delivery; it was $0.5 \mathrm{~g}$ higher in the offspring from the mothers which were treated with CsA compared to the offspring in the control group $(\mathrm{p}<0.05)$ (Table 2).

At 12 weeks of age, there were no significant differences with respect to body weight and kidney weight (Table 3). When separately analyzing the males and females of both groups, the kidney weight was statistically greater in the females from the exposed group than from the control group. 


\section{Kidney Blood Pressure Research}

Kidney Blood Press Res 2015;40:413-423

\begin{tabular}{l|l}
\hline DOI: $10.1159 / 000368515$ & C 2015 S. Karger AG, Basel
\end{tabular}

Published online: July 27, 2015

www.karger.com $/ \mathrm{kbr}$

Slabiak-Blaz/Adamczak/Gut/Grajoszek/Nyengaard/Ritz/Wiecek: Cyclosporine A and Kidney Development

Blood pressure and laboratory tests

At 7 and 11 weeks of age the systolic (SBP) and diastolic (DBP) blood pressures were significantly higher in the offspring of mother rats treated with CsA during gestation compared to the offspring of mother rats treated with solvent (Table 3). When separately analyzing the males and females of both groups, SBP and DBP at 7 weeks of age were significantly higher in the male and female offspring of mother rats from the exposed group compared to the offspring of the mothers from the control group. However at 11 weeks of age only DBP measured in female offspring of the mother rats treated with CsA during gestation were higher compared to the offspring of the mother rats treated with solvent.

The urinary albumin excretion rate was assessed at 11 weeks of age; it was increased in the offspring of pregnant rats treated with CsA compared to the offspring in the control group (Table 3). When separately analyzing the males and females of both groups, albuminuria was significantly higher in the female offspring from the exposed group compared to the female offspring from the control group. In the male offspring of mothers from the exposed group albuminuria was greater compared to the male offspring from the control group, but this difference did not reach the statistical significance, probably due to high standard deviation.

There was no difference between serum creatinine concentration and creatinine clearance in the two groups (Table 3).

\section{Number and volume of glomeruli}

At 12 weeks of age, the total number of glomeruli per kidney, N(glom), was significantly lower in the male or female offspring of dams treated with CsA $\left(19.5 \cdot 10^{3} \pm 758\right)$ compared with the male or female offspring of dams in the control group $\left(24.0 \cdot 10^{3} \pm 861\right)$ (Fig. 1 A, B, C).

Male or female offspring exposed during fetal life to CsA had significantly higher mean glomerular volume $\mathrm{Vn}$ (glom) than male or female offspring from the control group $(2.4 \pm 0.3$ $10^{6} \mu \mathrm{m}^{3}$ vs $1.7 \pm 0.210^{6} \mu \mathrm{m}^{3}$ ) (Fig. $2 \mathrm{~A}, \mathrm{~B}, \mathrm{C}$ ).

Total glomerular volume V(glomTotal) was significantly higher $(17.8 \%)$ in the CsA exposed group compared to the control group $\left(47.5 \pm 6.9 \mathrm{~mm}^{3} v s 40.3 \pm 5.1 \mathrm{~mm}^{3}, \mathrm{p}<0.001\right)$.

Qualitative assesment of glomerular, tubulointerstitial and vascular compartments

No signs of glomerular sclerosis were found in either groups. Except single atrophic tubuli and very small foci of fibrosis no signs of acute (like: thrombotic microangiopathy or isometric tubular epithelial vacuolization) and chronic (like: patchy atrophy in tubuli, striped fibrosis or hyalinosis in vessels) CsA nephrotoxicity was observed in tubulointerstitial and vascular compartment. There were no differences in qualitative analysis of tubulointerstitial and vascular compartment between the two groups. A representative cortical section was shown in Fig. 3.

\section{Discussion}

The study demonstrates that exposure to CsA in utero leads to low nephron endowment and increases blood pressure as well as albuminuria later in extrauterine life.

CsA is a commonly used as an effective immunosuppressive drug in the treatment of autoimmune diseases. According to current guidelines CsA is allowed for use during pregnancy. Therefore CsA treatment is continued during pregnancy in some women with autoimmune diseases. The same is true after organ transplantation.

Solid organ transplantation is nowadays recommended as best option of treatment for patients with end-stage kidney disease, liver disease or heart failure. Solid organ transplantation is associated with significant improvement in the quality of life, in overall longevity and also fertility. Therefore, it is not surprising that increasing numbers of pregnancies are reported in patients with kidney, liver, heart or lung transplants [20]. 


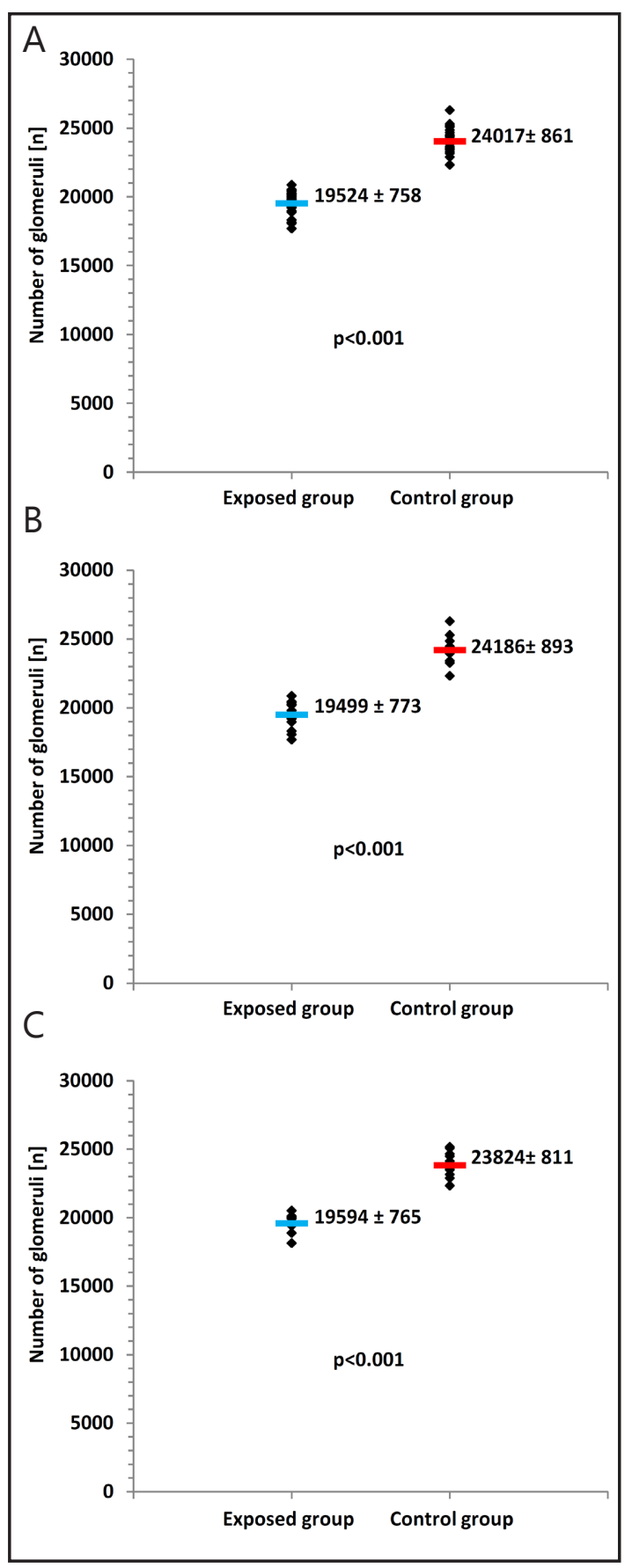

Fig. 1. Number of glomeruli in offspring exposed in utero to CsA and offspring exposed-to solvent (control group); A - entire group of offspring; B - male offspring; C - female offspring.

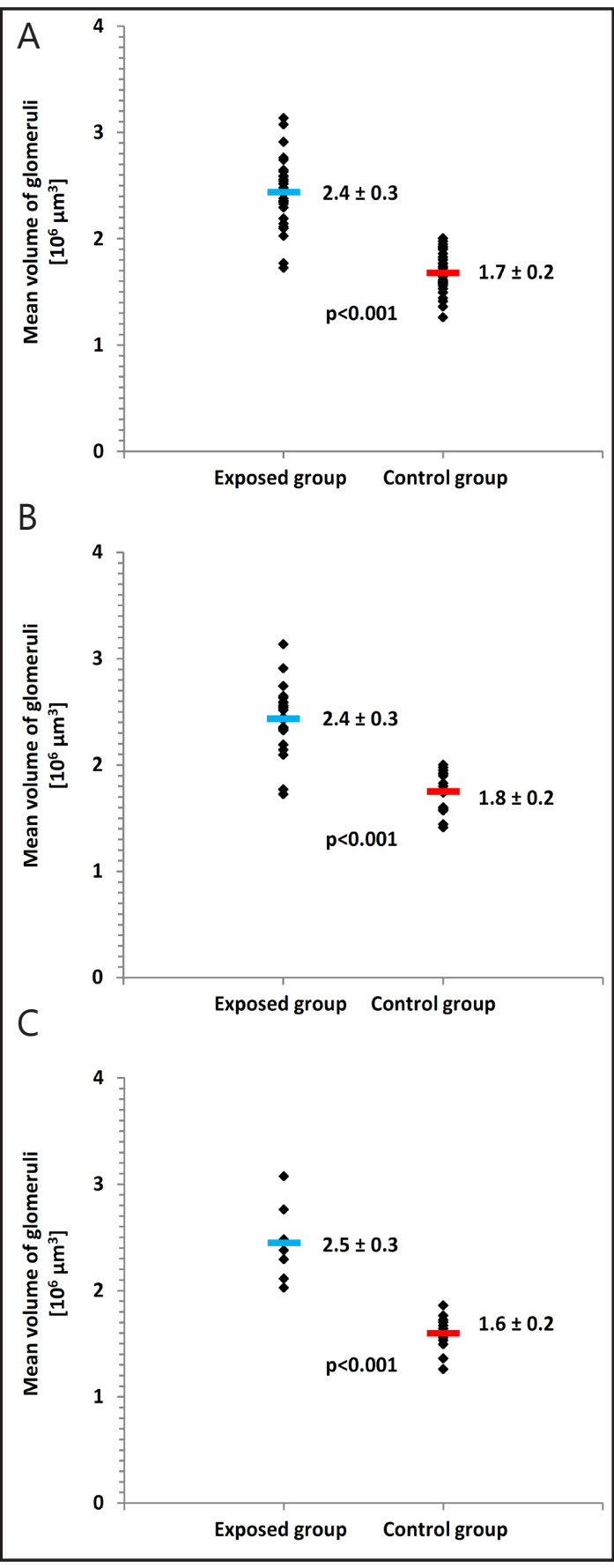

Fig. 2. Mean volume of glomeruli in offspring exposed in utero to CsA and exposed to solvent (control group); A - entire group of offspring; B - male offspring; C - female offspring.

Obviously after solid organ transplantation women must continue immunosuppressive treatment during pregnancy and accordingly CsA is routinely used in such patients. Little is known, however, about potential teratogenic effects of CsA. According to the National 


\section{Kidney \\ Blood Pressure Research}

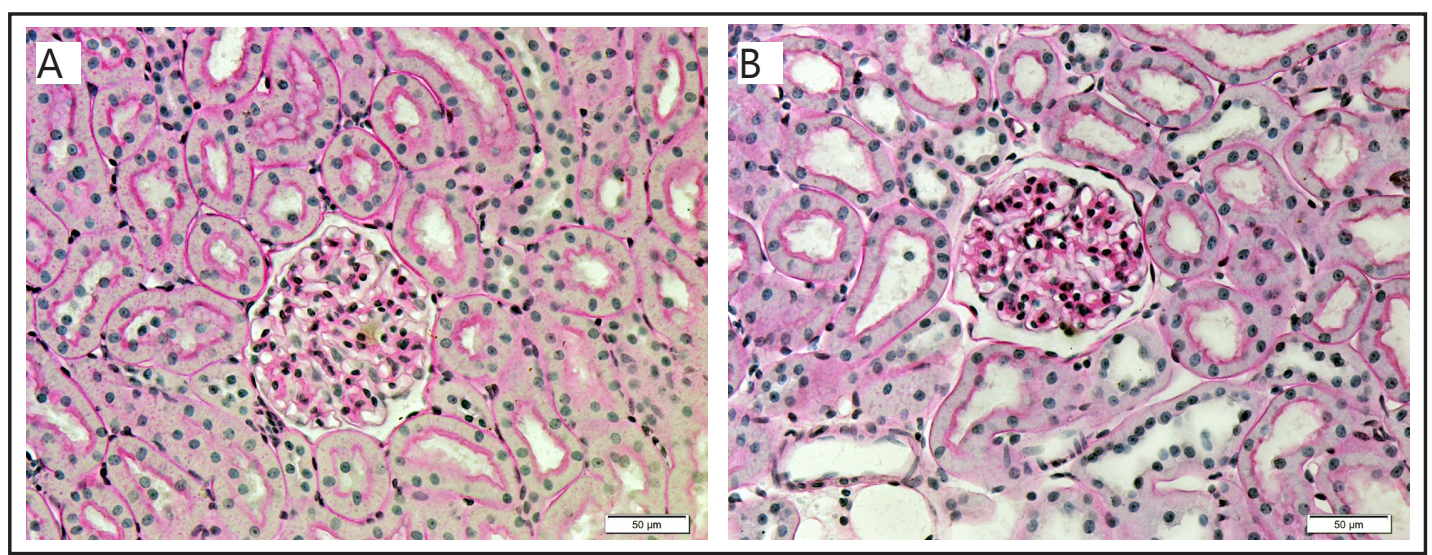

Fig. 3. Representative section of cortex in 12 weeks old offspring exposed in utero to CsA (A) and exposed to solvent (control group) (B) (PAS stained, magnification 200x).

Transplantation Pregnancy Registry the prevalence of major structural malformations in the offspring of mothers exposed to CsA was $4-5 \%$. This is comparable to the prevalence in the general population (3-5\%) [21].

Nevertheless, CsA crosses the placenta and may therefore potentially influence fetal development with the long-term result of subtle defects as a consequence of in utero exposure to immunosuppressive agents.

The present animal study using advanced stereological techniques documents that even rat offspring exposed to relatively low doses of CsA during fetal life have abnormal numbers and geometry of glomeruli, i.e. 19\% lower numbers and 45\% higher volumes compared to controls. These results suggest that exposure to CsA during fetal life interferes significantly with kidney development. It should be stressed that in our study we have used the physical fractionator/ disector technique which is now considered as a "gold standard" in stereology $[17,22]$. The number of glomeruli in offspring of Sprague-Dawley dams from control group is in agreement with data reported by others [9].

The present results corroborate and extend the findings obtained in rabbits by Tendron et al. [23]. In this study the relatively imprecise maceration method with $50 \%$ hydrochloric acid was used. The exposure to CsA was short (4 days) and a considerably higher (probably toxic) CsA dose $10 \mathrm{mg} / \mathrm{kg} /$ day was used. The latter point may explain the high (almost 50\%) reduction of the number of pups, as well as the finding of intrauterine growth-retardation (IUGR) of the pups with CsA exposure between 20 and 24 days of pregnancy [23].

It is well known that a decreased number of glomeruli is associated with both spontaneous and induced low birth weight [19]. In our study no difference in the number of pups was seen between pups exposed to CsA and the control group. The higher (on average $0.5 \mathrm{~g}$ ) body weight measured on the $2^{\text {nd }}$ day after delivery in CsA exposed offspring may be caused by longer weight gain in uterus. This certainly excludes the potential argument that the glomerular changes were the result of generalized CsA toxicity. We conclude that the glomerular abnormalities in our study are the result of a specific CsA effects on glomerulogenesis rather than the result of intrauterine growth retardation. The potential mechanisms causing reduced nephron endowment caused by exposure to CsA during fetal life need further studies. The low-protein model of nephron endowment in rats shows that mechanisms of fetal programming are complex, multifactorial and need cautious interpretation [24]. For example an influence on Wilms' tumour supressor gene 1 (WT1) expression during fetal life may affect not only nephron endowment but may alter podocyte structure or function and may also influence expression of other genes [25]. 


\section{Kidney Blood Pressure Research}

Kidney Blood Press Res 2015;40:413-423

DOI: $10.1159 / 000368515$

Published online: July 27, 2015

(C) 2015 S. Karger AG, Basel

www.karger.com/kbr

In the current study it was also found that at 11 weeks of age the animals from the group exposed to CsA had higher albuminuria compared to the offspring of the control group. In male offspring of mothers from the exposed group albuminuria was greater compared to the male offspring from the control group, but did not reach statistical significance. We believe that this is due to high standard deviation of albuminuria in this group.

Albuminuria is considered as an early marker of chronic kidney disease and according to Brenner it may result from hyperfiltration of the remaining glomeruli. Koleganova et al. [26] showed that offspring of mother rats on high vs low salt diet during pregnancy had lower nephron numbers and increased albuminuria. This paradigm may also be relevant in humans: low birth weight (which can be considered a surrogate marker for reduced nephron number) is related to an increased risk of chronic kidney disease in adulthood [27].

Beyond the glomerular abnormalities, we were also able in the present study to demonstrate that rat offspring exposed in utero to CsA had significantly higher SBP and DBP at 7 weeks of age. At 11 weeks of age only DBP measured in female offspring of mother rats treated with CsA during gestation were higher compared to the offspring of mother rats treated with the solvent. Many animal models of fetal programming found a different response to a prenatal insult according to sex. For example Ozaki et al. found that female offspring appear to be protected from or exhibit reduced sensitivity to a moderate insult during development [28]. In some models only a more severe insult (e.g. more severe protein restriction) leads to hypertension in both male and female offspring [29]. We measured blood pressure with the CODA tail-cuff system which uses the Volume Pressure Recording technology, which is an indirect method of blood pressure measurements. We interpret these findings with caution, since critical observers would expect measurements with the use of radiotelemetry methods.

In animal experiments, different insults during fetal life (e.g. protein deficiency, uterine ligation, hyperglycemia, antibiotics etc.), result in low nephron endowment; decreased nephron number leads to increased blood pressure. In humans a relationship between a low nephron number and increased risk of hypertension was also observed [10, 30, 31]. For example we found that exposure of pregnant rats to cigarette-smoke condensate causes higher blood pressure in their offspring - but in contrast to the present study such offspring were not characterized by a reduced nephron number, but by lower numbers of podocytes, mesangial-cells, and endothelial-cell numbers [32].

We cannot exclude that in utero exposure to CsA interferes not only with the development of the kidney, specifically the nephron number, but it may also interfere with the development of others organs e.g. blood vessels, heart, sympathetic nerve system; such sequelae might also contribute to the increased blood pressure. For example Tendron-Franzin et al. observed that rabbits exposed in utero to CsA had increased urinary excretion of endothelin-1 [33].

Apart from CsA, there are numerous different conditions (e.g. malnutrition [34], maternal deprivation of: protein [35], vitamin A [8] or vitamin D [36], placental insufficiency [37-39], the use of steroids [40] or ethanol [41] etc.) adversely influencing fetal development and the mechanisms leading to structural or functional changes in the developing fetus are complex [42-45].

Taken together, the above mentioned findings indicate that exposure to CsA during fetal life interferes with kidney development, resulting in reduced nephron endowment, and potentially increasing the risk of hypertension and chronic kidney disease in adulthood.

In humans, only a few studies assessed exposure to CsA in utero [14-16]. None of these studies found that exposure to CsA during fetal life is related to impaired kidney function or hypertension in extrauterine life. These studies however only included a small number of participants and were short-time studies. The longest observation post partum did not exceed 7 years [14]. 


\section{Kidney \\ Blood Pressure Research}

\section{Kidney Blood Press Res 2015;40:413-423}

\begin{tabular}{l|l}
\hline DOI: $10.1159 / 000368515$ & (C) 2015 S. Karger AG, Basel
\end{tabular}

Published online: July 27, 2015

www.karger.com/kbr

Our study has some limitations. The results of the present study clearly document that exposure to CsA during fetal life impacts on kidney development and increases blood pressure as well as albuminuria later in life. However the study fails to provide mechanistic insights. Future studies should address the potential roles of renal growth regulators, the renin-angiotensin-aldosterone system, reactive oxygen-related mechanisms and nitric oxide. Blood pressure was measured by an indirect method, i.e. rat tail with the use of CODA system. In the future preferably radiotelemetry should be used to measure blood pressure. Our experiment lasted 12 weeks, but rats live more than 100 weeks and we may have missed late complications. Finally we performed a single-endpoint observation in offspring at a young age; it will be interesting to observe in the future any eventual late adverse outcomes.

Nonetheless, our experimental rat study provides a strong rationale for long-term studies in the human population to assess how exposure to CsA in fetal life can potentially influence the risks of developing hypertension and chronic kidney disease in adult life. This will be important for early prophylaxis or treatment of chronic kidney disease and hypertension in subjects exposed to CsA in utero.

\section{Conclusion}

This study documents that exposure to CsA during fetal life influences normal kidney development and might thus predispose to chronic kidney disease and hypertension in adult life.

\section{Disclosure Statement}

The authors of this manuscript state that they do not have any conflict of interests and nothing to disclose.

\section{Acknowledgments}

The authors thank H. Andersen, A.M. Wiss, Z. Antoni for their excellent technical support, and Dr. Henryk Karkoszka for the qualitative analysis of glomerular, tubulointerstitial and vascular compartments, and Monica Fontana Faughnan for the linguistic assistance.

This research has been supported by a Silesian Medical University, Katowice, Poland, grant nr: KNW-1-073/N/3/0. Centre for Stochastic Geometry and Advanced Bioimaging is supported by Villum Foundation. Natalia Slabiak-Blaz was supported by fellowship of ERAEDTA.

\section{References}

1 Barker DJ: The developmental origins of adult disease. J Am Coll Nutr 2004;23:588S-595S.

2 Brenner BM, Chertow GM: Congenital oligonephropathy and the etiology of adult hypertension and progressive renal injury. Am J Kidney Dis 1994;23:171-175.

3 Brenner BM, Garcia DL, Anderson S: Glomeruli and blood pressure: Less of one, more the other? Am J Hypertens 1988;1:335-347.

4 Brenner BM, Lawler EV, Mackenzie HS: The hyperfiltration theory: a paradigm shift in nephrology. Kidney Int 1996;49:1774-1777.

5 Brenner BM, Mackenzie HS: Nephron mass as a risk factor for progression of renal disease. Kidney Int 1997;63:S124-S127. 


\section{Kidney \\ Blood Pressure Research}

Kidney Blood Press Res 2015;40:413-423

\begin{tabular}{l|l}
\hline DOI: $10.1159 / 000368515$ & (C) 2015 S. Karger AG, Basel
\end{tabular}

Published online: July 27, 2015

www.karger.com/kbr

6 Woods LL, Ingelfinger JR, Nyengaard JR, Rasch R: Maternal protein restriction suppresses the newborn renin-angiotensin system and programs adult hypertension in rats. Pediatr Res 2001;49:460-467.

7 Celsi G, Kistner A, Aizman R, Eklöf AC, Ceccatelli S, de Santiago A, Jacobson SH: Prenatal dexamethasone causes oligonephronia, sodium retention, and higher blood pressure in the offspring. Pediatr Res 1998;44:317-322.

8 Lelièvre-Pégorier M, Vilar J, Ferrier ML, Moreau E, Freund N, Gilbert T, Merlet-Bénichou C: Mild vitamin A deficiency leads to inborn nephron deficit in the rat. Kidney Int 1998;54:1455-1462.

9 Gray SP, Denton KM, Cullen-McEwen L, Bertram JF, Moritz KM: Prenatal exposure to alcohol reduces nephron number and raises blood pressure in progeny. J Am Soc Nephrol 2010;21:1891-1902.

10 Keller G, Zimmer G, Mall G, Ritz E, Amann K: Nephron number in patients with primary hypertension. N Engl J Med 2003;348:101-108.

11 Bar Oz B, Hackman R, Einarson T, Koren G: Pregnancy outcome after cyclosporine therapy during pregnancy: a meta-analysis. Transplantation 2001;71:1051-1055.

12 Venkataramanan R, Koneru B, Wang CCP, Burckart GJ, Caritis SN, Starzl TE: Cyclosporine and its metabolites in mother and baby. Transplantation 1988;46:468-469.

13 Gilbert T, Gaonach S, Moreau E, Merlet-Bénichou C: Effect of cyclosporin A (CsA) on rat metanephros differentiation in vitro. J Am Soc Nephrol 1994;5:623A.

14 Cochat P, Decramer S, Robert-Gnansia E, Dubourg L, Audra P: Renal outcome of children exposed to cyclosporine in utero. Transplant Proc 2004;36:208S-210S.

15 Giudice PL, Dubourg L, Hadj-Aïssa A, Saïd MH, Claris O, Audra P, Martin X, Cochat P: Renal function of children exposed to cyclosporine in utero. Nephrol Dial Transplant 2000;15:1575-1579.

16 Shaheen FAM, Alsulaiman MH, Alkhader AA: Long-term nephrotoxicity after exposure to ciclosporine in utero. Transplantation 1993;56:224-225.

17 Nyengaard JR: Stereologic methods and their application in kidney research. J Am Soc Nephrol 1999;10:1100-1123.

18 Slabiak-Blaz N, Adamczak M, Wystrychowski A, Ritz E, Więcek A: Pharmacokinetics of cyclosporine A, tacrolimus and sirolimus given subcutaneously in normal rats. Nefrol Dial Pol 2013;17:53-55.

19 Schreuder MF, Nyengaard JR, Fodor M, van Wijk JA, Delemarre-van de Waal HA: Glomerular number and function are influenced by spontaneous and induced low birth weight in rats. J Am Soc Nephrol 2005;16:2913-2919.

20 Mc Kay DB, Josephson MA: Pregnancy after kidney transplantation. Clin J Am Soc Nephrol 2008;3:S117-S125.

21 Zachariah MS, Tornatore KM, Venuto RC: Kidney transplantation and pregnancy. Curr Opin Organ Transplant 2009;14:386-391.

22 Bertram JF: Counting in the kidney. Kidney Int 2001;59:792-796.

23 Tendron A, Decramer S, Justrabo E, Gouyon JB, Semama DS, Gilbert T: Cyclosporine A administration during pregnancy induces a permanent nephron deficit in young rabbits. J Am Soc Nephrol 2003;14:3188-3196.

24 Rookmaaker MB, Joles JA: The nephron number counts - from womb to tomb. Nephrol Dial Transplant 2013;26:1325-1328.

25 Menendez-Castro C, Hilgers KF, Amann K, Daniel C, Cordasic N, Wachtveitl R, Fahlbusch F, Plank C, Dötsch J, Rascher W, Hartner A: Intrauterine growth restriction leads to a dysregulation of Wilms' tumour supressor gene 1 (WT1) and to early podocyte alterations. Nephrol Dial Transplant 2013;28:1407-1417.

26 Koleganova N, Piecha G, Ritz E, Becker LE, Müller A, Weckbach M, Nyengaard JR, Schirmacher P, GrossWeissmann ML: Both high and low maternal salt intake in pregnancy alter kidney development in the offspring. Am J Physiol Renal Physiol 2011;301:F344-F354.

27 Hallan S, Euser AM, Irgens LM, Finken MJJ, Holmen J, Dekker FW: Effect of intrauterine growth restriction on kidney function at young adult age: The Nord Trøndelag Health (HUNT 2) Study. Am J Kidney Dis 2008;51:10-20.

28 Ozaki T, Nishina H, Hanson MA, Poston L: Dietary restriction in pregnant rats causes gender related hypertension and vascular dysfunction in offspring. J Physiol 2001;530:141-152.

29 Woods LL, Ingelfinger JR, Rasch R: Modest maternal protein restriction fails to program adult hypertension in female rats. Am J Physiol Regul Integr Comp Physiol 2005;289:R1131-1136. 


\section{Kidney \\ Blood Pressure Research}

Kidney Blood Press Res 2015;40:413-423

DOI: $10.1159 / 000368515$

Published online: July 27, 2015

(C) 2015 S. Karger AG, Base

www.karger.com/kbr

Slabiak-Blaz/Adamczak/Gut/Grajoszek/Nyengaard/Ritz/Wiecek: Cyclosporine A and Kidney Development

30 Hoy WE, Hughson MD, Singh GR, Douglas-Denton R, Bertram JF: Reduced nephron number and glomerulomegaly in Australian aborigines: a group at high risk for renal disease and hypertension. Kidney Int 2006;70:104-110.

31 Hughson MD, Douglas-Denton R, Bertram JF, Hoy WE: Hypertension, glomerular number, and birth weight in African Americans and white subjects in the southeastern United States. Kidney Int 2006;69:671-678.

32 Zarzecki M, Adamczak M, Wystrychowski A, Gross ML, Ritz E, Więcek A: Exposure of pregnant rats to cigarette-smoke condensate causes glomerular abnormalities in offspring. Kidney Blood Press Res 2012;36:162-171.

33 Tendron-Franzin A, Gouyon JB, Guignard JP, Decramer S, Justrabo E, Gilbert T, Semama DS: Longterm effects of in utero exposure to cyclosporine A on renal function in the rabbit. J Am Soc Nephrol 2004;15:2687-2693.

34 Gilbert JS, Lang AL, Grant AR, Nijland MJ: Maternal nutrient restriction in sheep: hypertension and decreased nephron number in offspring at 9 months of age. J Physiol 2005;565:137-147.

35 Hoppe CC, Evans RG, Moritz KM, Cullen-McEwen LA, Fitzgerald SM, Dowling J, Bertram JF: Combined prenatal and postnatal protein restriction influences adult kidney structure, function, and arterial pressure. Am J Physiol Regul Integr Comp Physiol 2007;292:R462-R469.

36 Reichetzeder C, Chen H, Föller M, Slowinski T, Li J, Chen YP, Lang F, Hocher B: Maternal vitamin D deficiency and fetal programming--lessons learned from humans and mice. Kidney Blood Press Res 2014;39:315-329.

37 Zhang S, Regnault TR, Barker PL, Botting KJ, McMillen IC, McMillan CM, Roberts CT, Morrison JL: Placental adaptations in growth restriction. Nutrients 2015;7:360-389.

38 Jansson T, Powell TL: Role of the placenta in fetal programming: underlying mechanisms and potential interventional approaches. Clin Sci (Lond) 2007;113:1-13.

39 Li J, Chen YP, Dong YP, Yu CH, Lu YP, Xiao XM, Hocher B: The impact of umbilical blood flow regulation on fetal development differs in diabetic and non-diabetic pregnancy. Kidney Blood Press Res 2014;39:369377.

40 Seckl JR, Holmes MC: Mechanisms of disease: glucocorticoids, their placental metabolism and fetal 'programming' of adult pathophysiology. Nat Clin Pract Endocrinol Metab 2007;3:479-488.

41 Gray SP, Kenna K, Bertram JF, Hoy WE, Yan EB, Bocking AD, Brien JF, Walker DW, Harding R, Moritz KM: Repeated ethanol exposure during late gestation decreases nephron endowment in fetal sheep. Am J Physiol Regul Integr Comp Physiol 2008;295:R568-R574.

42 Schreuder M, Delemarre-van de Waal HA, van Wijk A: Consequences of intrauterine growth restriction for the kidney. Kidney Blood Press Res 2006;29:108-125.

43 Miao Z, Chen M, Wu H, Ding H, Shi Z: Comparative proteomic profile of the human placenta in normal and fetal growth restriction subjects. Cell Physiol Biochem 2014;34:1701-1710.

44 Alwasel SH, Kaleem I, Sahajpal V, Ashton N: Maternal protein restriction reduces angiotensin II AT1 and AT2 receptor expression in the fetal rat kidney. Kidney Blood Press Res 2010;33:251-259.

45 Langley-Evans SC: Developmental programming of health and disease. Proceed Nutr Soc 2006;65:97-105. 